\title{
Differential conditioning based on concentration of sucrose reinforcement in rats on a VI schedule'
}

\author{
KENNETH P. GOODRICH ${ }^{2}$ \\ UNIVERSITY OF WISCONSIN
}

\begin{abstract}
Seven rats received extended bar-pressing training on a VI schedule with $8 \%$ and $32 \%$ sucrose reinforcement. During days in which $32 \%$ and $8 \%$ alternated in 10-min. stimulus-correlated periods, response rate and speed of the first response were greater for $32 \%$ solution. The possible contribution to such results of reinforcement contrast is discussed.
\end{abstract}

\section{Problem}

Few studies have been reported of differential conditioning based on different amounts of reinforcement (excluding nonreinforcement). The present experiment was conducted to explore the feasibility of studying differential conditioning based on two concentrations of sucrose reinforcement in a bar-pressing situation.

\section{Method}

The Ss were seven male Holtzman albino rats with initial free-feeding weights between 380 and $410 \mathrm{gm}$. Throughout the experiment Ss were maintained at $80 \%$ of these weights.

The apparatus consisted of a modified Gerbrands rat chamber with two Lehigh Valley rat levers (the left one nonfunctional), a cue light over each lever, a dim houselight, and a liquid delivery system. The delivery system consisted of a recessed drinking magazine with two motor-driven dippers which could separately deliver $.05 \mathrm{cc}$ of sucrose solution to a single hole in the floor of the magazine. The cue lights and a clicker mounted outside the chamber could be operated 10 times per second as discriminative stimuli.

Pretraining (Phase 1) for the first five Ss was one day of magazine training with concurrent CRF and two days of CRF alone. About 100 reinforcements of $32 \%$ solution were received each day. Pretraining for the other two Ss began in a similar fashion except $4 \%$ solution was used. When it became clear that these Ss were not going to work for $4 \%$ solution (cf. Estes, 1959 , p. 435), they received 10 additional days of CRF with $4 \%, 8 \%$ and (in one case) $32 \%$ solution, and five days on a VI 1-min. schedule with $8 \%$ solution. For all Ss, two stimulus conditions alternated in 5-min. periods in each session. Stimulus A was the houselight only. Stimulus B was the houselight plus the blinking lights over the levers.

Following pretraining all Ss underwent extended training on a VI 1-min. schedule with $32 \%$ sucrose reinforcement (Phase 2). The first four Ss had 56 such sessions, the fifth had 51 sessions, and the last two had 30 sessions. During the last 25 of these sessions and continuing until the last phase of the experiment, a reinforcement was set up with the onset of each stimulus period. Eight 5-min. stimulus periods occurred in alternation each day.

In Phase 3, the two stimulus components, A and B, were consistently associated with the two solutions, $32 \%$ and $8 \%$, respectively. Alternate days began with $A$ and $B$ components and assignment of dippers to solutions was balanced over days. As in Phases 2 and 4, the basic reinforcement schedule was VI 1-min. For the first 31 sessions the stimulus periods were as in the previous phases. During the last 13 sessions and continuing for the remainder of the study, the number of daily periods was reduced to six, each period became $10 \mathrm{~min}$. in duration, and the click was added as an additional component to Stimulus A.

During the 43 sessions of Phase 4, procedures differed on alternate days. On test days, Ss continued as in Phase 3 except that Stimulus A always began the session. On control days, Ss received 60 consecutive minutes of Stimulus A with $32 \%$ solution. During the first 23 days of this phase, reinforcements were set up at the beginning of each stimulus period on test days and at the beginning of each 10-min. interval on control days. During the final 20 sessions no reinforcements were set up in the first minute of each successive 10-min period.

\section{Results and Discussion}

The two sucrose solutions had very little differential effect for the first 31 sessions of Phase 3. In three Ss there was no discernible effect, in two Ss there was some slight suggestion of faster responding for the $32 \%$ solution, and for two other Ss there was a consistent but small superiority of the $32 \%$ solution. Following the lengthening of the periods to $10 \mathrm{~min}$. and the addition of the click to Stimulus A, faster responding for $32 \%$ solution rapidly emerged in all seven Ss. In all cases, this differential responding represented a decreased rate for the $8 \%$ solution compared with the previous performance, and in three Ss there was also an increase in rate for the $32 \%$ solution. Unfortunately, the role of the added click cannot be separated from that of the longer period in facilitating differential responding. Greater stimulus discriminability, more consecutive reinforcements of one kind, or both, could have been involved. In any case, previous use of a similar click in this laboratory, and the fact of decreasing rates for the $8 \%$ solution in Stimulus B, make it unreasonable to interpret the differential responding as a direct activation by the click. 
Figure 1 presents a summary of results for the first half of Phase 4. With one exception noted below, the picture was the same for the last half during which reinforcement was not available during the first minute of each period. Although the data in Fig. 1 are means of $\mathrm{Ss}^{8}$ means over 20 sessions, the results were the same for the four combinations of group means and medians with individual means and medians. The central finding was that response rate was higher in the first minute and over all $10 \mathrm{~min} .$, and latency of the first response was shorter, for periods with $32 \%$ reinforcement than for comparable periods with $8 \%$ reinforcement. For the rate measures there was no overlap in the scores for all relevant comparisons within test days or between test and control days. For latency, all Ss showed a shorter mean latency in Period 5 than in Period 4 and much the same overall pattern as in Fig. 1. The differences in rate remained fairly constant during the session, whereas the differences in latency increased. Consistent with other bar-pressing results (e.g., Collier \& Siskel, 1959), absolute performance declined within sessions.

The finding that response rate on a VI schedule is a function of sucrose concentration confirms Guttman's results (1954) and complements work with FI and FR schedules (e.g., Collier \& Siskel, 1959; Hurwitz, Walker, Salmon, \& Packham, 1965). The results for response latency, a measure not often used with bar pressing, provide a clear demonstration of differential conditioning (acquired stimulus control) based on reinforcement amount, complementing the runway results of Bower (1961) and Goldstein \& Spence (1963). Rate of response was also under stimulus control, as shown during the last 20 sessions by faster responding in the first minute of Stimulus $\mathrm{A}$, before a reinforcement with $32 \%$ solution had yet been received, than in the first minute of Stimulus $B$.

An interesting question for further research is the contribution to results such as those reported here of reinforcement contrast, defined roughly as a change in the efficacy of one reinforcer by its contrast with another reinforcer. Perhaps at each stimulus change the newly available sucrose concentration is contrasted with the previous amount so as to inflate the reinforcing value of $32 \%$ solution or deflate the value of $8 \%$ solution. The finding of Keesey \& Kling (1961) that effects of reinforcement amounts on VI responding in pigeons appeared immediately after a stimulus change signaling a change in amount of reinforcement but disappeared over the next $40 \mathrm{~min}$. might be interpreted with a contrast mechanism.

As for the present data, the effect of contrast on responding for $32 \%$ solution may be assessed by comparing performance during Periods 3 and 5 on control days with that on test days. The left panel

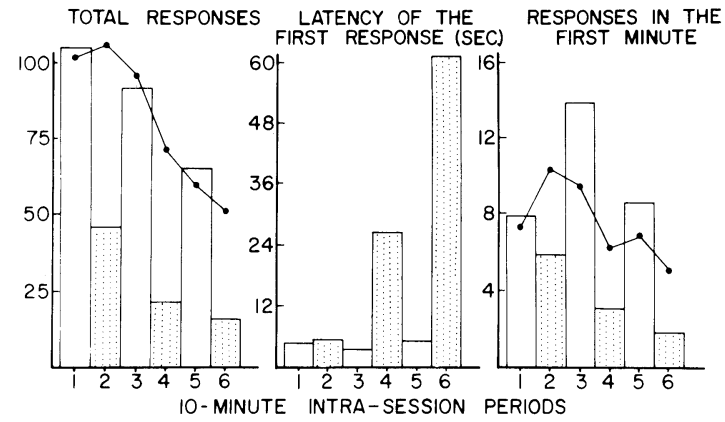

Fig. 1. Group means of individual means over 20 sessions. Bar graphs indicate responding on test days for $32 \%$ (open bars) and $8 \%$ (stippled bars) solutions Connected points indicate responding on control days $(32 \%$ solution)

in Fig. 1 shows that response rate over $10 \mathrm{~min}$. for $32 \%$ solution was not inflated by contrast with the $8 \%$ solution in the preceding period. The apparent contrast effects which may be seen during the first minute of Periods 3 and 5 (right panel) may have resulted less from contrast than from the stimulus change signaling the set-up of reinforcement on test days. Consistent with this possibility is the fact that the apparent contrast effects were greatly attenuated, while the overall difference between $8 \%$ and $32 \%$ conditions remained the same, during the last 20 sessions in which reinforcement was not permitted during the first minute of each period. Unfortunately, the effeets of contrast on responding for the $8 \%$ solution cannot be assessed because there was no control condition involving $60 \mathrm{~min}$. of $8 \%$ reinforcement (cf. Bower, 1961). Further work will be required to determine the role of contrast in results such as those reported here and by Keesey \& Kling (1961).

\section{References}

Bower. G. A contrast effect in differential conditioning. $J$. exp. Psychol., 1961, 62, 196-199.

Collier, G, \& Silkel, M., Jr. Performance as a joint function of amount of reinforcement and inter-reinforcement interval. $J$. exp. Psychol., 1959, 57, 115-120.

Estes, W. K. The statistical approach to learning theory. In S Koch (Ed.), Psychology: a study of a science. Vol. 2, New York: McGraw-Hill, 1959.

Goldstein, H., \& Spence, K. W. Performance in differential conditioning as a function of variation in magnitude of reward. $J$. exp. Psychol., 1963, 66, 86-93.

Guttman, N. Equal-feinforcement values for sucrose and glucose solutions compared with equal-sweetness values. J. comp. physiol. Psychol., 1954, 47, 358-361.

Hurwitz, H. M. B., Walker, S. F., Salmon, E. A., \& Packham, D. The effects of two sucrose solutions on rate of response under a fixed ratio schedule. Psychol. Rec., 1965, 15, 145-150.

Keesey, R. E., \& Kling, J. W. Amount of reinforcement and freeoperant responding. J. exp. Anal. Behav., 1961. 4, 125-132.

Notes

1. Supported in part by NIH Grants MH-04528 and FR-00167.

2. Now at Macalester College. 